gliomas. However, the perfusion method has many demerits. We prefer a continuous intra-arterial infusion of anticancer drugs for the chemotherapy of gliomas and other intracranial malignant tumors.

A silicone coating polyethylen tube, $0.8 \mathrm{~mm}$ in diameter, was inserted into the internal carotid artery and it was connected to a slow speed injection pump with a long tube, through which $50 \mathrm{mg}$ of Methotrexate was continuously iufused a day for from 3 weeks to 3 months, and $60 \mathrm{mg}$ of folic acid was injected simultaneouly into the muscle every 6 hours as an antidote against Methotrexate.

The results of the continuous infusion was interpreted by observing neurological syndrome, bulging at the external cranial decompression, arteriograms, pneumoencephalograms, ultrasonic encephalograms.

The results could be confirmed in 20 cases out of 24 cases with brain tumors which underwent continuous infusion. Among 20 cases, results were excellent in 9 cases, moderate in 5 cases, and non-effective in 6 cases. The results were excellent in 7 out of 12 cases with gliomas and 7 out of 8 cases with metastatic maligmant tumors or primary intracranial sarcomas.

These results showed that the continuous infusion was not so effective in the cases with gliomas as in the cases with other malignant tumors and in the former cases a duration of the continuous infusion has to be not less than 3 weeks at least for getting some clinical effects.

The most significant noxious side effect of the continuous infusion is a brain edema. Therefore, it may be considered that a decompression craniotomy is indispensable before this treatment.

\title{
S-B-5. Radiation Therapy of Glioma
}

\author{
Tsutomu WATARI
}

Dept. of Radiology, University of Tokyo

\section{S-B-6. Radiation Therapy of Glioma}

\author{
Tadashi MiYagawa \\ Dept. of Radiology, University of Tokyo
}

